\title{
Nota de l'Equip de Redacció
}

Amb aquest número 98/1, Papers. Revista de Sociologia inicia el seu primer any com a revista exclusivament electrònica (vegeu la "Nota de la redacció» publicada al número 97/2). L’Equip de Redacció pensem que aquesta nova etapa obre interessants possibilitats de dedicar esforços i recursos a augmentar la visibilitat i viabilitat de la revista tot incrementant també la seva qualitat científica. En aquest sentit, el nou web s'inscriu dins d'aquesta línia de millora del posicionament de la revista en l'àmbit virtual.

Així mateix, i en consonància amb aquests canvis, l'any 2012 va tenir lloc una profunda renovació del Consell de Redacció de la revista, que ha anat acompanyada d'una implicació més gran dels membres d'aquest a les tasques quotidianes de filtre previ d'articles i presa de decisions editorials sobre aquests. Volem agrair des d'aquestes pàgines la col-laboració i la fidelitat dels membres del Consell anterior, molts dels quals han passat a formar part del Consell Consultiu, i donar la benvinguda a les noves incorporacions.

Finalment, també volem anunciar un canvi en la nostra política de seccions. A partir de l'any 2013, la revista deixarà de publicar notes d'investigació i notes bibliogràfiques, i s'obrirà a propostes per a una nova secció de debats sobre aportacions o temes d'especial interès per a les ciències socials. Els canvis que hem introduït a les normes de la revista reflecteixen aquesta nova política. Les seccions d'articles i de ressenyes bibliogràfiques, per descomptat, es mantenen. De manera excepcional, en el present número incloem la traducció al català d'un text clàssic de Robert K. Merton d'especial interès per a la sociologia, prologat i contextualitzat pel seu traductor, Xavier Gimeno.

L'Equip de Redacció 


\section{Nota del Equipo de Redacción}

Con este número 98/1, Papers. Revista de Sociologia inicia su primer año como revista exclusivamente electrónica (véase la «Nota de la redacción» publicada en el número 97/2). El Equipo de Redacción pensamos que esta nueva etapa abre interesantes posibilidades de dedicar esfuerzos y recursos a aumentar la visibilidad y viabilidad de la revista al tiempo que se incrementa también su calidad científica. En este sentido, la nueva web se inscribe dentro de esta línea de mejora del posicionamiento de la revista en el ámbito virtual.

Así mismo, y en consonancia con estos cambios, el año 2012 tuvo lugar una profunda renovación del Consejo de Redacción de la revista, que ha ido acompañada de una mayor implicación de sus miembros en las tareas cotidianas de filtro previo de artículos y toma de decisiones editoriales sobre los mismos. Queremos agradecer desde estas páginas la colaboración y la fidelidad de los miembros del anterior Consejo, muchos de los cuales han pasado a formar parte del Consejo Consultivo, y dar la bienvenida a las nuevas incorporaciones.

Finalmente, queremos anunciar también un cambio en nuestra política de secciones. A partir del año 2013, la revista dejará de publicar notas de investigación y notas bibliográficas, y se abrirá a propuestas para una nueva sección de debates sobre aportaciones o temas de interés para las ciencias sociales. Los cambios que hemos introducido en las normas de la revista reflejan esta nueva política. Las secciones de artículos y de reseñas bibliográficas, por descontado, se mantienen. De manera excepcional, en el presente número incluimos la traducción al catalán de un texto clásico de Robert K. Merton de especial interés para la sociología, prologado y contextualizado por su traductor, Xavier Gimeno.

El Equipo de Redacción 